\title{
4
}

\section{The Global Diffusion of Adult Basic Education}

\author{
Fabian Besche-Truthe
}

\section{Introduction ${ }^{1}$}

Adult Basic Education (ABE) policies regulate and ensure access to training in basic reading, writing, and numeracy skills for those who did not have the chance to attain these skills in formal education. The policies are supposed to advance individuals' economic possibilities and foster inclusion into society at large (e.g., UNESCO 2015). As a policy field, $\mathrm{ABE}$ is situated between education policy and active labor market policy (ALMP) as well as being ingrained in human rights discourses. Data on first introductions of ABE policy show an accelerating surge in

\footnotetext{
${ }^{1}$ This chapter is a product of the research conducted in the Collaborative Research Center "Global Dynamics of Social Policy" at the University of Bremen. The center is funded by the Deutsche Forschungsgemeinschaft (DFG, German Research Foundation)-project number 374666841-SFB 1342.
}

F. Besche-Truthe $(\varangle)$

SOCIUM, University of Bremen, Bremen, Germany

e-mail: fbesche@uni-bremen.de 
national policy adoption from the 1960s onwards. This chapter empirically investigates the spread of $\mathrm{ABE}$ policies all over the globe. In my analysis, I take domestic variables into account, but focus primarily on nation states' interdependencies. As we know from the extensive canon of policy diffusion research (e.g., Gilardi 2016; Obinger and Schmitt 2011; Dobbin et al. 2007), clustered policy adoption involves communication between actors. Thus, diffusion essentially happens in multiplex networks through which actors are connected to each other (Valente 1995). This chapter highlights the diffusion of $\mathrm{ABE}$ policies by asking: What are the main network determinants for the adoption of first $\mathrm{ABE}$ legislation? In my analysis, I draw on the global network data that is used throughout this edited volume. Precisely, these networks are depicting cultural similarity, colonial legacies, trade, and geographic proximity.

The adoption of $\mathrm{ABE}$ policy marks a political act in which actors, at least nominally, problematize the existence of adults without formal schooling and consciously opt for taking on the problem as a matter of the nation state. It becomes a responsibility which needs to be institutionalized in law. Passing a policy, however, does not at all safeguard its implementation. Nonetheless, with policy adoption countries signal their valuation of the policy's theorized impact and gain legitimacy in the global system of nation states. Adopting a policy on ABE makes sense economically and rationally as well as from a human rights perspective. Countries not adopting would have the burden of proof for non-adoption.

This chapter advances on the de jure adoption of $\mathrm{ABE}$ as both a compensatory and a preventive social policy. On the one hand, it is targeted at adults (and often adolescents) who fell through the cracks in the formal education system, i.e., compensating for inferiority in children's education, sometimes being called "second chance education" (UNESCO Institute for Statistics 2012, 25). On the other hand, education in general and adult education in particular are framed as directly impacting the economic and social development of an individual, thereby preventing later costs for the social security system (e.g., World Bank 1995); essentially following the logic of better (or any institutionalized) education equals better and safer (regular) jobs. Especially the Organization for Economic Co-Operation and Development 
$(\mathrm{OECD})$ is a key player in connecting skills with economic progress (e.g., https://oecdskillsforjobsdatabase.org).

While the influence of IOs on global education discourses is unquestionable, the diffusion of $\mathrm{ABE}$ policy is still a blind spot with little to no global macro studies. Using network diffusion analysis, I aim to estimate the influence of networked relations of nation states on ABE policy adoption. This chapter progresses with a short introduction of the global discourse on $\mathrm{ABE}$ and the topic itself. After a brief section on theories of policy diffusion, I will turn to the empirical part testing possible hypotheses on the influence of domestic as well as relational variables. Lastly, I will present the estimations and draw conclusions that ought to motivate future research.

\section{Adult Basic Education}

Global discourse on institutionalized adult education started in 1949 when the UNESCO commenced the first "Conférence Internationale sur l'Education des Adultes" (CONFINTEA) in Helsingør, Denmark-a recurring conference bringing together policymakers, NGOs and experts on topics concerning adult education (Knoll 2008).

A Google Ngram (in Appendix) suggest, discourse on "Adult Education" as well as its French translation peaked in the 1950s but stayed at a high rate until decreasing in the 1980s, only to be exceeded by the more encompassing term "Lifelong Learning". IOs like the UNESCO and specifically its sister organization the UNESCO Institute for Lifelong Learning (UIL) were of significant impact in the emergence and evolution of international conversations on the issues of lifelong learning (LLL) and, accordingly, adult education (Jakobi 2009). This chapter focuses on the diffusion of one part of the vast thematic complex of LLL, which is adult basic education. The "Recommendation on Adult Learning and Education", which was adopted at the UNESCO General Conference in 2015, states that adult education comprises informal, non-formal, and formal education which aims at fostering adults' participation in society and work (UNESCO 2015, 6). The idea of developing and enriching capabilities for living and working give those learning 
schemes a very important role in the education system of the respective state. This chapter deals with ABE policy as the constitutive part of state-led adult education endeavors, which are also specifically targeted at marginalized groups.

There are several ways of raising the skill level of a society, but offering basic education to those who did not gain any formal education in childhood is, in combination with widening access to school education in general, the most effective. It is situated in an ingrained human rights discourse in which "Education for All" problematizes the existence of unor undereducated adults. The topic of adults' skill development indisputably gained importance in global education and economic policy (Jakobi 2009, 55f.). Debate increased despite isolated critiques from the World Bank (Torres 2009), mainly concerned with missing returns on investment in adult education in general. Nevertheless, ABE policies have spread around the globe quite rapidly.

The map in Fig. 4.1 depicts the de jure adoptions of ABE policies for 164 countries. In comparison to other social policies dealt with in this volume, the map shows that diffusion of $\mathrm{ABE}$ policies started rather late with Finland in 1921 as the first country to introduce; followed by Turkey in 1929, and the USSR as well as Germany in 1957 and 1953,

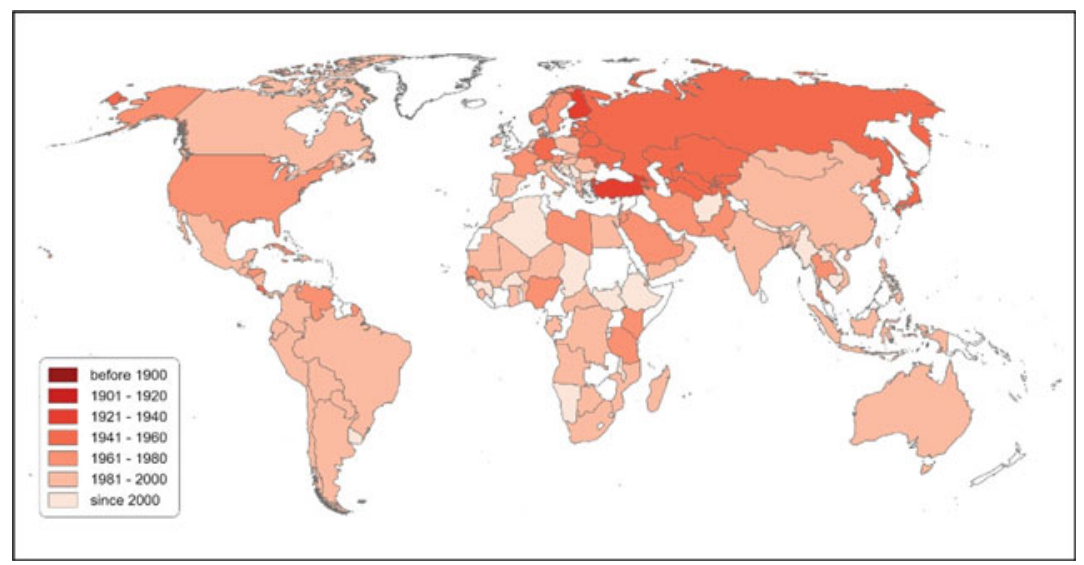

Fig. 4.1 ABE policy adoption map 
respectively. The bulk of adoptions started in the 1960s and accelerated in the 1990s and 2000s (see below).

The UNESCO has been pushing for adult education since its foundation (Jakobi 2009, 67f.) with its "Conférence Internationale sur l'Education des Adultes" (CONFINTEA) hosted by the UIL. The 1985 conference in Paris "established a new right- the right to learn for all, throughout life. Special attention was to be paid to marginalized groups such as women, youth, the elderly, minorities [...]" (Bhola 1989, 57).

Now, virtually all IOs active in education or economy refer to the strategy of learning and skill formation throughout the whole lifetime as key for successful education and economic systems (see, e.g., OECD 2012; UNESCO 2017; World Bank 2003; World Conference on Education for All 1990); intergovernmental organizations follow the same path (European Council 2011; African Union 2016). The rise in attention to the educational needs of adults is part of the general universalizing trend in education. According to Weymann, inclusive education for everyone at every stage of their life is the "undisputed normative goal" (2016, 19; translation by author). The goal is to create equal opportunities by providing access to adequate competences and knowledge and avoiding the emergence of a disadvantaged group of both low- and not formally skilled workers (see Spilker 2013, 102).

\section{Theories of Policy Diffusion}

The mechanisms behind global policy adoption trends can be as diverse as policies themselves. Indeed, one of the main ideas behind this edited volume is to test different assumptions within different (social) policy fields. Dobbin et al. (2007) describe four major theoretical strands when it comes to diffusion research: constructivism, coercion, competition, and learning. Elkins and Simmons (2005) take a stricter route when they confine diffusion to a process driven by uncoordinated interdependence. In its rawest form, in this volume, diffusion is defined as "any process where prior adoption of a trait or practice in a population alters the probability of adoption for remaining non-adopters" (Strang 1991, 325). With these mechanisms and definitions in mind, it is no surprise that 
a myriad of scholars has argued for different paths of policy diffusion. These paths are, furthermore, very diverse depending on the policy field and, sometimes, on the country sample used. In the following, I attempt to summarize past evidence and theoretical bases that might be relevant for the diffusion of ABE. Accordingly, I introduce the networks which serve to depict possible diffusion avenues.

\section{Constructivism}

In a constructivist view, policy adoption is a matter of ideology with policies representing appropriate and legitimate means to important ends. Both are socially constructed, thus, shifting over time and space (Dobbin et al. 2007, 451). Especially in the field of education policy, a lot of scholarship is situated in neo-institutionalist accounts, which, in its purest form, is the most popular in the constructivist camp. These scholars see shifts in recognizing problems that are universal to all states and bring up universal solutions for those problems rooted in the world society (Meyer et al. 1997). All around the globe, actors, including nation states, legitimize themselves by holding on to universally legitimized world models like citizenship, the need for education, capitalist economy, etc. The supposedly "best" models gain such a strength that their raison d'être is their rationality, legitimization without being questioned, and universal applicability (Meyer et al. 1997).

$\mathrm{ABE}$ being framed as a human right is both an indicator for the normative institutionalization as well as cause for further institutionalization. Spilker finds that (in Germany) the discourse on educational opportunities has shifted toward risk groups that, due to a lack of education, are unable to participate in the globalized world $(2013,74)$. Illiteracy and lack of skills are major problems that need to be tackled by governments, creating an enormous pressure on states to enact policies. Refusal to offer new educational opportunities through $\mathrm{ABE}$ appears as a failure to render assistance (Spilker 2013, 225). Moreover, the global discourse specifically targets whole political entities that are not sufficiently participating in the globalized world (e.g., UNESCO 2017). 
The emergence of the norm of formally skilled and educated citizens of every age is shaping policies all over the globe. The norm itself is shaped and carried throughout the international sphere not only by states but especially through professionals and epistemic communities which are most likely found in IOs and science (Meyer et al. 1997, 166). In this light, the "institutional conditions for diffusion" (Strang and Meyer 1993) and not national differences are key in understanding the phenomenon itself. Diffusion is greatly accelerated in instances where actors fall into the same category and conceptions of formal organizations are institutionalized (Strang and Meyer 1993, 490-491). For the latter that means that "theoretical accounts of practices simplify and abstract their properties and specify and explain the outcomes they produce" (Strang and Meyer 1993, 497). Actors, on the other hand, are theorized as sufficiently similar so that practices can have similar effects all over the globe.

The ensuing institutionalization culminates in an impressive isomorphism of state structures and policies that are not easily explained by classic functionalist theories. Consider, for example, the cumulative adoption plot in Fig. 4.2: On the $x$-axis one sees the year of observation and the $y$-axis represents the percentage of countries in the specific World Bank income group that have adopted an ABE policy. We can discern that the general trend of policy adoptions only started in 1960 and accelerated until almost 90\% of high-income and around 70\% of low-income countries adopted an ABE policy. Differences in slopes between the income groups are hardly visible. This is in line with neoinstitutionalist theory, in that the global discourse seems to render other influences nugatory. Following this logic, one would assume no statistically significant influence of either national factors or interdependencies. On the other hand, a lot of scholars decidedly diverge from the teleological neo-institutionalism. Though I am unable to test the underlying micro-mechanisms of policy adoption, I aim at testing the influence of the macro-structures nation states have built. In line with this edited volume, it is clear that countries have multiplex ties with one another, i.e., they have ties in different dimensions. I regard these networks as the underlying structure through which communication, and, hence, diffusion happens. This underlying structure can be best explained by 


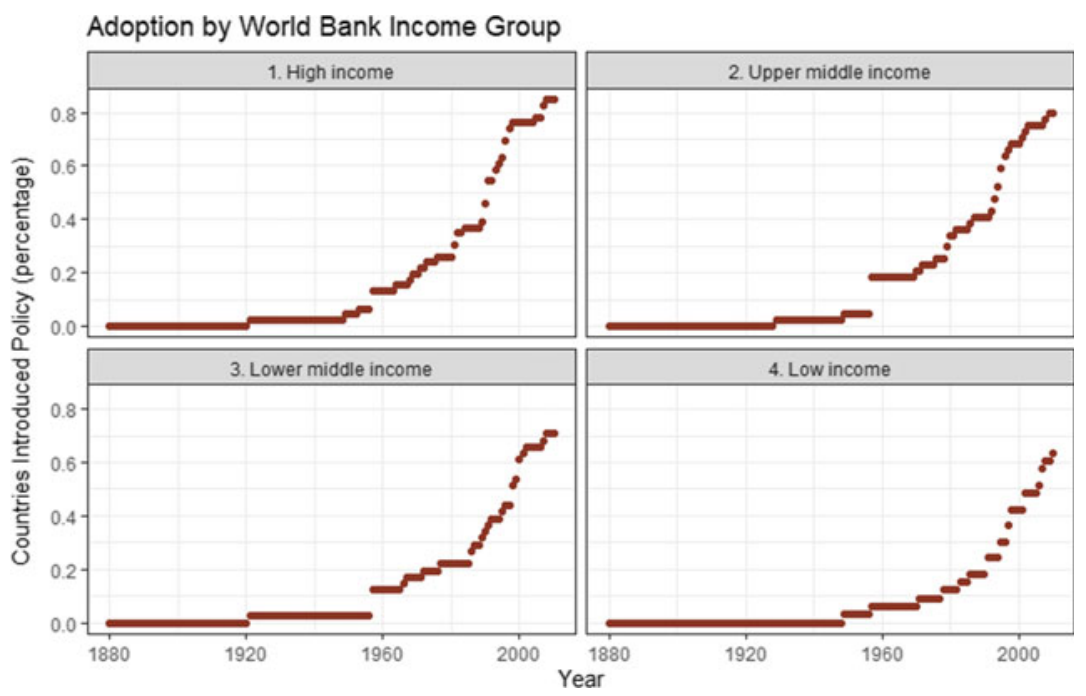

Fig. 4.2 $A B E$ policy adoptions by income group

a "pipe-structure" (Martens and Windzio 2021). The innovation, in this case $\mathrm{ABE}$ policy, travels through the pipes and actors that are exposed to other actors that already adopted a policy should have a higher risk of adopting the policy itself (see below). The underlying structures, investigated in this chapter, are cultural similarity, colonial legacies, trade, and spatial proximity. In the following, I will give a short overview of all these structures.

\section{Cultural Similarity}

Since education is inherently intertwined with culture, i.e., is reproduced by and reproduces specific cultural configurations, being exposed to a culturally similar country that has already introduced ABE might prove influential. The influence of world society is not ignored, but rather thought to be not as influential as neo-institutionalists would suspect. Hence, external ideational influences are translated into cultural configurations and, thereby, probably so much skewed that the general pattern 
of adoptions of $\mathrm{ABE}$ policies is affected. For instance, values of meritocracy, i.e., the individual being the locus of development, would prompt a state to address under-education when the problem comes up in political debate (Ramirez 1989). On the other hand, adoptions of ABE might be delayed in countries that show more familialistic community structures. In these compositions, the penetration of the global discourse might take longer to be actualized through policy (Pfau-Effinger 2005; Boli et al. 1985). This would constitute waves of diffusion in which the exposure inside cultural spheres has an impact on the rate of adoption. For this purpose, I will estimate the effects of a network of cultural similarities. The basis for that is a two-mode network which connects countries with cultural characteristics such as dominant religion, civil and gender liberties, government ideology, and language group (for a detailed description see Chapter 1 in this volume). Through a one-mode projection on the country set, the resulting network links countries to one another if they share cultural characteristics. Furthermore, the ties are weighted by the number of shared characteristics and through their time-variant nature, the network is time-variant itself (Besche-Truthe et al. 2020). With this approach, we build a flexible and more encompassing definition of culture which shows overlapping cultural spheres rather than rigid boundaries between groups of countries. Staying true to the pipe metaphor, one can discern that the more similar countries are, the larger the pipe is through which $\mathrm{ABE}$ policy can diffuse.

\section{Colonial Legacies}

In a world full of power imbalances coercion theorists argue that hegemonic actors exercise a lot of influence over weaker actors. I include a network depicting power imbalances as countries' colonial relations. Contrary to some widely used operationalization like, e.g., the Gravity Model by CEPII in which a colonial tie is constant over time and either existent or non-existent, this network is based on time-variant data spanning as far back as the sixteenth century and includes formerly overlooked forms of "colonization" such as the Ottoman Empire or the USSR. The raw data stems from the COLDAT dataset by Becker (2019). 
Additionally, I am able to not only catch "imperial diffusion" (Kuhlmann et al. 2020, 85) but account for past colonial relationships as well. Thus, I assume the influence of a previous colonial power that has already ended getting proportionally smaller to the currently existing colonial power. When the country then becomes completely independent, the proportions of influence no longer differ from each other (for a detailed description see Chapter 1 in this volume). Since a comprehensive theory describing the mechanism of post-colonial ties between countries on policy diffusion in a macro-perspective is missing, I use the possibility to report a second operationalization of the experience of colonial legacy, in that they have an overall declining strength on the diffusion process (see Appendix). Lastly, the network is directed-which means I assume that only the metropole influences the diffusion process and not vice versa.

In the colonial ties network, I expect to find metropoles which introduced $\mathrm{ABE}$ and which extended the policy to countries still under colonial rule (Kuhlmann et al. 2020). This could be especially valid for tight colonial interlinkages based on political ideologies. For instance, Obinger and Schmitt (2011) demonstrate that social policy making was subject to political regime competition during the Cold War. Introducing policies to advance the average education of the work force not only helps in technological advancement but keeps (colonial) subjects satisfied and "in line" with the current ideology by projecting a caring state as well as promising opportunities for better pay in higher skilled jobs. Additionally, former colonies receive a significantly higher amount of donations from their former occupiers than other countries (Shields and Menashy 2019). Furthermore, former colonies, to some extent, orientate themselves toward the metropoles either positively or negatively. On the one hand, policies might be emulated because they appear on the public agenda and are perceived as valuable (Dobbin et al. 2007, 453). Path dependencies laid out through institutionalizations during the period of colonization might play a huge role as well (Kuhlmann et al. 2020). On the other hand, knowledge about policy adoptions in former metropoles could very well culminate in a strong retention of this very policy, which would manifest in a negative or at least non-significant relation. In short, relations with a higher intensity might increase the possibility for contact 
and orientation on policy models of the metropole, especially because this network can catch possible path-dependencies that started with colonization. Nevertheless, the opposite could be true, which would manifest itself in negative coefficients.

\section{Trade and Geography Network}

Based on Marxist research, policies are increasingly influenced by interlinkages of countries as a direct result of economic and social globalization (Dale 1999). We see the influence mostly in policies with direct impacts on the economy, e.g., neoliberal tax policy (Swank 2006). Diffusion is rarely observed for policies that take a long time to become fruitful like infrastructure investments (Dobbin et al. 2007, 458). If economic competition plays a huge role in policy diffusion, one would expect reinforcement of existing power imbalances. Already powerful countries could have larger impacts on the spread of policies than weaker countries; with, for instance, Swank showing the pivotal role of US tax policy in the neo-liberalization of Western tax regimes (Swank 2006). On a similar note, Jahn (2006) shows a "race to the bottom" in social spending through economic ties in the OECD.

Also, research on active labor market policies in the EU shows freerider effects of neighboring countries (Franzese and Hays 2006). I suspect these effects to also be visible in the global trade network: If one country has the upskilling policy of $\mathrm{ABE}$ in place, it might demotivate a strongly connected country to implement the same, thus slowing the diffusion process. Although education expansion has been shown to be a result of a growing integration into the global economy (Griffiths and Imre 2013, 51), it is unclear what to expect when taking the trade network as structural basis for the diffusion of ABE policy. Especially in this case, the intermediary role between education and ALM policy might dampen economic impacts. The data used to build an undirected time-variant trade network were drawn from the "Correlates of War Project" (Barbieri and Keshk 2016). Total trade values between two countries were logarithmically transformed and are used as relational weights (for a detailed description see Chapter 1 in this volume). 
Lastly, I consider countries' geographic proximity as a structure of the multiplex ties which aides in establishing communication channels through which diffusion can happen. In this network, countries are more strongly connected the geographically nearer they are to each other (for a detailed description see Chapter 1 in this volume). With increased proximity, I believe, the probability of direct connection of large numbers of the population, cross-border work arrangements, politically institutionalized meetings, research endeavors, etc. increases as well. Additionally, a neighboring country serves in most cases as a more prominent ground for comparison. Exposure to policies in the geographic proximity network is, therefore, a catch-all indicator which still can show significant influence on the diffusion of ABE policies (Maggetti and Gilardi 2016, 93). Thus, it functions as a control variable which non-geographic interdependencies need to withstand. More directly, however, in combination with education and skills, we find these effects of positive externalities through policies of adjacent states for example in the phenomenon of brain drain. The 2019 Global Education Monitoring Report, for instance, finds that persons who emigrate are on average highly educated (UNESCO 2018, 38). If the supply of adults with basic skills is met through immigration from nearby countries, a state would not need to invest in basic skills of its own population. By looking at geographic proximity and trade relations, I hope to consider free-rider effects, especially in circumstances of positive externalities (see also Franzese and Hays 2006).

\section{Methods}

The empirical part of this chapter will test the influence of the described networks as structural bases for diffusion. As dependent variable, first introductions of $\mathrm{ABE}$ policies were collected for $N=164$ countries. I define $\mathrm{ABE}$ as education targeted at adults with low or no proficiency in basic skills, with the explicit aim to teach these skills. For instance, the North Macedonian Law on Primary Education (Official Gazette of R. Macedonia No. 44/95) qualifies because in Article 6 it stipulates: "The primary education of adults can be organized in a mainstream primary school" (emphasis added by Fabian Besche-Truthe). Another example 
would be the Brazilian Lei de Diretrizes e Base da Educação Nacional section V, article 37, which determines that adult education should be geared toward those who did not have either access to or continuity in primary and secondary education at the right age. It is the first actual mentioning of $\mathrm{ABE}$ in Brazilian federal education laws, despite its long history of literacy campaigns from civil society. These civil society literacy programs, however, do not qualify as being coded, with this chapter dealing with the momentum of nation states taking responsibility in ABE.

In accordance with the edited volume at hand, the time frame of inquiry spans from 1880 to 2010. Although the first introduction happened in 1921, in theory, countries were at risk of adopting an $\mathrm{ABE}$ policy at all times. The exposure variables have been calculated using the netdiffuseR package (Yon and Valente 2017), and I predict hazard ratios by using a discrete-time logistic hazard model. Network exposure is calculated as the weighted average of alters that already adopted ABE policy ego is connected to. If, for instance, ego trades equally with two countries, and one of them has already adopted ABE policy, the exposure would be $1 / 2=0.5$. For all networks, the weights distinguishing between strong and weak connections are taken into account (for a detailed description see Chapter 1 in this volume).

To control for time-dependency, i.e., unobserved heterogeneity, I control for time as a piecewise constant rate function. Other chapters in this volume choose rather steady time intervals of 25 years each, but I diverge from this operation because, first, since adoptions start quite late, I would assess time periods without any event which would greatly distort the estimation. Secondly, in accordance with theories described above, I believe the global discourse to have a great determining effect on the overall susceptibility of nation states to introduce $\mathrm{ABE}$ policies. Thus, I make use of the CONFINTEA as the determining cut points of time slices. Figure 4.3 shows these points in accordance with counts of yearly adoptions. Especially the conference in Paris was revered by Western countries claiming that a new "right to education for all" was instituted (Bhola 1989). Other commentators simply see the conference as a shift toward a neo-liberalist direction (Knoll 2008, 141). Indeed, one can surmise a spike in yearly adoptions between the conferences of Paris in 


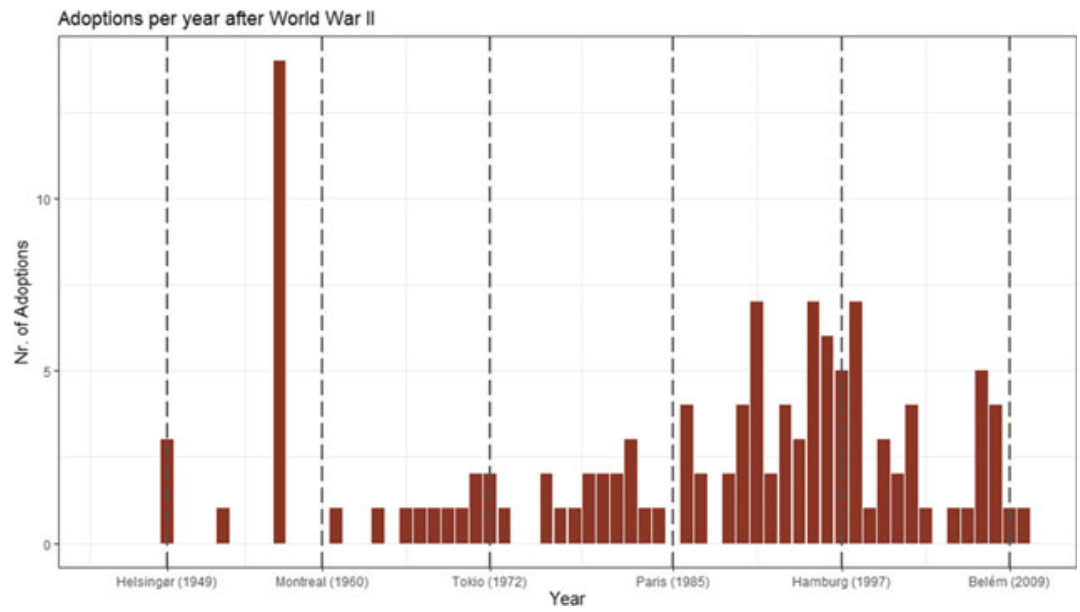

Fig. 4.3 ABE policy adoptions per year (Note The largest number of adoptions [third bar from the left] is due to the USSR introducing ABE which is automatically valid for a high number of single countries as well)

1985 and Hamburg in 1997. All in all, this builds the base of a vertical, i.e., top-down, diffusion against which other effects and interdependencies need to align. Technically it means that for every period between conferences a new baseline hazard of policy adoption is assumed.

As control variables, I introduce GDP per capita (Inklaar et al. 2018) and levels of democratization (Lührmann et al. 2018). Both have been interpolated for missing data points as described in Chapter 1 of this volume. Including the former is supposed to control for both economic performance and states' financial capabilities. I presume that more educated persons are needed if high economic performance should be maintained. Moreover, economic performance serves as a proxy for state budgetary opportunities to actually implement ABE policy which would make it more likely that the policy is adopted in the first place.

Also, I suspect the more democratic a system is, the more possibility there is for participation and actively trying to influence political decisions toward more social spending (Lindert 2004), which includes opening education for the masses. On the other hand, democracies might 
prove resilient to $\mathrm{ABE}$ because marginalized groups have less opportunity to actually participate although it is a free democracy. As shown by Paglayan (2021), autocracies have expanded school education by a large margin to keep the populace in line. Education is here a double-edged sword, it serves as enculturation in the nation state's will but at the same time can give individuals the means to overthrow the status quo (Griffiths and Arnove 2015, 91). Though the USSR is among the first actors to introduce $\mathrm{ABE}$, other non-democratic regimes fall into the group of late adopters.

Lastly, I include a variable representing the problem pressure. My suspicion is straightforward: The higher the number of adults without formal educational attainment is, the higher is the pressure to implement $\mathrm{ABE}$ as a salvation for these individuals and a quick upskilling of the population. Thus, I depict the percentage of adults without any formal schooling attainment, i.e., they did not finish primary school (Barro and Lee 2015). Also, high rates of persons with no formal schooling should make the global discourse fall on open ears more easily. Especially because IOs might publicly problematize these statistics while depicting them as easily fixable through adult education policies. Furthermore, with the average of formally unskilled adults over extended periods of time, I do, in part, proxy the general capabilities, performance and past importance of formal, state-led education. Large values indicate a suboptimal inclusion rate as well as a potential undervaluing of the state's formal education. The data in five-year intervals has been linearly interpolated.

Finally, I face a problem with non-independent observations: There are historical time periods in which several countries did not exist because they were part of a larger, embracing unit, e.g., Croatia was part of Yugoslavia. In the following network diffusion model, I address this statistical non-independence by correcting for heteroscedasticity with robust standard errors (for a detailed description see Chapter 1 in this volume). 


\section{Results}

Table 4.1 presents results of the discrete time logistic hazard estimations in hazard ratios. These are interpretable analogously to odds ratios, i.e., a positive relationship is signified by ratios larger than 1 and a negative relationship by estimations between 0 and 1 .

Table 4.1 Diffusion of adult basic education

\begin{tabular}{|c|c|c|c|c|c|c|}
\hline & (1) & (2) & (3) & (4) & (5) & (6) \\
\hline $1880-1948$ & $0.0003^{* * *}$ & $0.0003^{* \star *}$ & $0.0001^{* * *}$ & $0.0001^{\star \star \star}$ & $0.0001^{* \star *}$ & $0.0003^{* * *}$ \\
\hline 1949-1959 & $0.009^{* * *}$ & $0.008^{* * *}$ & $0.002^{* \star *}$ & $0.002^{* * *}$ & $0.003^{* * *}$ & $0.007^{* * *}$ \\
\hline 1960-1971 & $0.003^{* * *}$ & $0.003^{* * *}$ & $0.0005^{* * *}$ & $0.0005^{* * *}$ & $0.001^{* * *}$ & $0.003^{* * *}$ \\
\hline 1972-1984 & $0.005^{* * *}$ & $0.004^{* * *}$ & $0.001^{* * *}$ & $0.001^{* * *}$ & $0.002^{* * *}$ & $0.004^{* * *}$ \\
\hline 1985-1996 & $0.008^{* * *}$ & $0.005^{* * *}$ & $0.001^{* * *}$ & $0.001^{* * *}$ & $0.005^{* * *}$ & $0.008^{* * *}$ \\
\hline $1997-2010$ & $0.003^{* * *}$ & $0.002^{* * *}$ & $0.001^{* * *}$ & $0.001^{* * *}$ & $0.004^{* * *}$ & $0.006^{* *}$ \\
\hline $\begin{array}{l}\text { trade existed } \\
\quad(=1, \text { else }=0)\end{array}$ & & & $7.171^{* *}$ & $7.269^{* *}$ & 3.547 & 2.336 \\
\hline $\begin{array}{l}\text { cultural spheres } \\
\text { netw.: w. } \\
\text { exposure (lag } \\
1 \text { year) }\end{array}$ & $59.900^{* *}$ & $61.677^{\star *}$ & $120.875^{* * *}$ & $51.247^{+}$ & 12.720 & 27.508 \\
\hline $\begin{array}{l}\text { colonies netw.: } \\
\text { w. exposure }\end{array}$ & & $2.277^{\star *}$ & $2.357^{\star *}$ & $2.337^{\star *}$ & $2.803^{*}$ & $2.635^{*}$ \\
\hline $\begin{array}{l}\text { trade netw.: w. } \\
\text { exposure (lag } \\
1 \text { year) }\end{array}$ & & & $0.158^{\star *}$ & $0.138^{\star *}$ & 0.332 & $0.099^{*}$ \\
\hline $\begin{array}{l}\text { spatial } \\
\text { proximity } \\
\text { netw.: w. } \\
\text { exposure (lag } \\
1 \text { year) }\end{array}$ & & & & 3.485 & 0.940 & 0.999 \\
\hline $\begin{array}{l}\text { GDP per } \\
\text { capita/US\$10,000 }\end{array}$ & & & & & 1.103 & 1.118 \\
\hline democratization & & & & & 1.038 & 1.043 \\
\hline $\begin{array}{l}\text { percentage } \\
\text { adults w/o } \\
\text { schooling }\end{array}$ & & & & & 0.993 & $0.980^{*}$ \\
\hline $\begin{array}{l}\text { trade netw.: w. } \\
\text { exposure: } \\
\text { percentage } \\
\text { adults w/o } \\
\text { schooling }\end{array}$ & & & & & & $1.041^{+}$ \\
\hline Observations & 18,190 & 18,190 & 18,190 & 18,190 & 14,445 & 14,445 \\
\hline Log Likelihood & -598.944 & -591.409 & -581.906 & -581.431 & -476.715 & -473.804 \\
\hline Akaike Inf. Crit & 1211.888 & 1198.819 & 1183.811 & 1184.862 & 981.429 & 977.607 \\
\hline
\end{tabular}

Note ${ }^{+} p<0.1 ;{ }^{*} p<0.05 ;{ }^{* *} p<0.01 ;{ }^{* * *} p<0.001$ 
The six models presented here are built in an additive fashion, introducing exposure in different networks one at a time and subsequently adding national factors as controls. After several estimations, I opted to include the interaction effect of exposure in the trade network and problem pressure. The significance levels as well as model fit statistics justify this decision.

First, while refraining from substantially interpreting the effects of the different time slices, it is worth noting that they are all significant and somewhat differing in size. That means that the baseline hazard to adopt ABE policy is different considering the time between CONFINTEA meetings and the highest after the one in Paris (19851997). Although this might reflect other similar global or domestic developments, I suspect it as being consistent with the neo-institutional account of differing strengths of norms in world society.

Exposure to culturally similar countries that already adopted an $\mathrm{ABE}$ policy proves to be a significant positive influence even when considering exposure in some other networks. In combination with the spatial proximity network, it is only significant on the $10 \%$ level and after including the pressure variable, the effect becomes insignificant, hinting at only a small role of culture in the diffusion process. On the other hand, the colonial ties network has a robust and positive effect on the adoption risk. Regardless of additional variables, the estimated hazard ratio stays almost the same with, e.g., $2.635^{*}$ in the last model. One confounding influence, however, is that Russia, being defined as a colonizer, influences the adoption of ABE policy in almost all USSR countries. Indeed, when deleting these countries from the estimation and running the models again, exposure in the colonial ties network no longer proves to be a significant influence (see Table 4.3 in Appendix).

Trade, as hypothesized, has a negative influence on the risk of adoption of $\mathrm{ABE}$ all models. This leads me to believe that strong trade relations with a country that already had implemented $\mathrm{ABE}$ decreases the adoption risk. The estimation, however, shows a huge limitation: through estimating an interaction with problem pressure we see that exposure in trade networks affects countries with differing strengths.

As shown in Fig. 4.4 a country with a large formally unskilled population has a higher risk of policy adoption with exceeding exposure in 


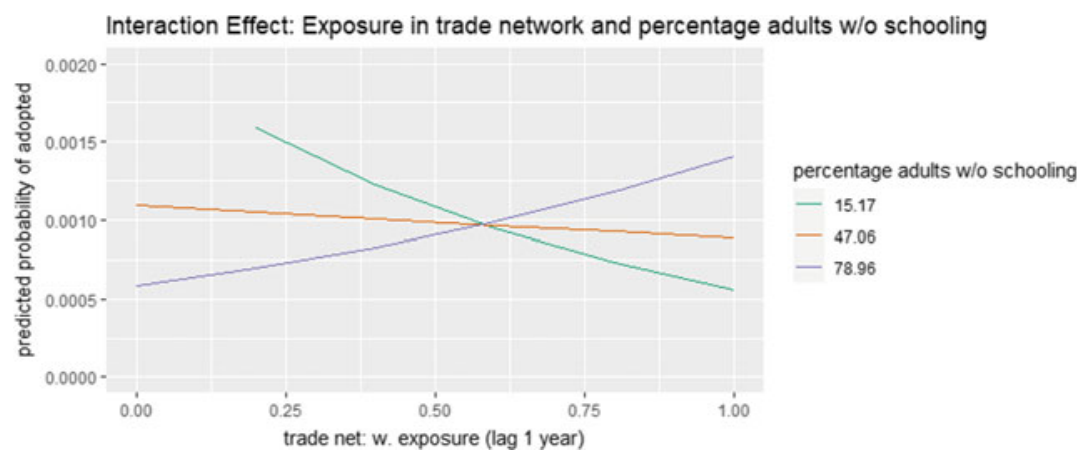

Fig. 4.4 Interaction effects (Note The graph shows the predicted probabilities of adopting $A B E$ in relation to exposure in the trade network. The lines represent the change in predicted probabilities for a country with the mean percentage of adults without formal schooling [47.06] as well as for countries with a value of one standard deviation below [15.17] or beyond [78.96] the mean)

the trade network than countries with generally lower percentages of unskilled adults. Exposure in the trade network still has a negative effect on risks of policy adoption, however, the smaller the percentage of adults with formal education gets, the more dampened is this effect. Although this difference through interaction is quite small, it hints at the free-rider effects described by Franzese and Hays (2006) being stronger in countries with larger shares of formally educated adults, e.g., OECD countries.

The described effects even hold against controlling for geographic exposure to $\mathrm{ABE}$ policies. It makes it all the more enlightening to see the robustness with the coefficients being not strongly affected by controlling for exposure through spatial proximity as well as economic development and democratization.

In sum, we can for certain discern two specific network effects. On the one hand, links through (past) colonial relationships significantly increase the risk of adopting. Hence, we see a case of imperial diffusion (Kuhlmann et al. 2020) in that the USSR's early adoption of ABE policies impacted all the dependent countries as well. Not considering USSR countries in the regression estimation, while still having them contribute to network exposure, makes democratization borderline significant on the $10 \%$ level, though with a rather small coefficient of $1.087^{+}$(see 
model 1 in Table 4.3 in Appendix). This somewhat hints at a certain degree of regime competition between the East and West, in that democratic non-USSR states seem to have a slightly higher risk of adopting, all other things equal.

On the other hand, high exposure to trade partners that already adopted $\mathrm{ABE}$ decreases the risk of policy adoption for countries by the quite large factor of $0.099^{*}$, although a higher margin of formally uneducated adults slows this dampening effect down. Nevertheless, with a total adoption rate of $75 \%$ the diffusion itself will probably not be entirely stopped.

Lastly, considering the operationalization of an overall receding influence of colonial legacies, i.e., non-normalized exposure rates, only a few differences are discernable. The results, presented in Table 4.2 in the Appendix, clearly affirm the weakness of the previously mentioned interaction effect since it loses significance. Solely the main effect of the percentage of adults without formal schooling shows a negative influence on the adoption risk, corroborating the assumption that a weak state education system slows down the adoption of new (inclusive) education policies. Again, not considering USSR countries in the estimation shows that exposure through colonial ties is, although significant in the full sample, mainly influenced by the USSR (see Appendix Table 4.3).

\section{Conclusion}

This chapter dealt with the diffusion of policies on adult basic education by estimating the effects of network determinants on the adoption of first ABE policy. I stressed the policy as marking a specific political act in which states problematize the existence of adults without formal schooling and consciously opt for taking on the problem as a matter of the nation state. In that regard, $\mathrm{ABE}$ with its preventive and compensatory rectification intersects not only with human rights discussions and extensions but also fits into the spread of human capital theory after 
World War II. The surge is mirrored in the concurrent adoptions of ABE policies which sped up in the 1980s and 1990s. By 2010 almost $90 \%$ of all countries assessed had introduced ABE policy. I utilized network diffusion analysis to macro-quantitatively assess which of the multiplex ties of countries around the globe were most prevalent. In doing so, I utilized four different social networks, connecting countries to each other: cultural similarity, colonial legacies, trade, and spatial proximity. I hypothesized that especially the global discourse in the world society is very influential in the diffusion. Following neo-institutionalist theory, domestic variables as well as interlinkages would be rendered nugatory over time.

Accordingly, the results show no striking effects. Cultural similarity, which shows a strong influence on the diffusion of generic education policies, has no robust influence in the case of ABE. On the other hand, exposure through colonial ties and operationalized in two different ways significantly increases the risk of policy adoption. That is, however, a sign of imperial diffusion of the USSR imposing upskilling policies on its satellite states.

Lastly, one can discern possible free-rider effects in that exposure in the trade network tends to decrease the adoption risk more strongly for countries that have a low number of formally uneducated adults than it does for countries with a large percentage of adults without formal schooling. Nevertheless, the effect is small and weak.

In a nutshell, all the results lead me to believe in a diffusion process that might not be fully erratic but is also not structured through interdependencies between countries. With these results in mind, it is worth considering neo-institutionalist accounts (e.g., Meyer et al. 1997) which predicted these results. Policies travel around the world and get more and more dispersed. I believe that ABE policies get adopted because of "taken-for-granted" knowledge of their usefulness and necessity, rather than via any diffusion mechanism that is discernable on this macro-level.

Nevertheless, what has not been considered is the decidedly strong discursive power of IOs on topics like ABE, lifelong learning, and education systems in general. As "rational others" (Meyer et al. 1997, 156), IOs 
have the opportunity to influence countries either directly or indirectly to adopt policies. This assumption does not claim that IO influence is per se harmful or actually forces countries to adopt policies they otherwise would despise; it just confirms that more research needs to be done on how IOs maneuver, change, and influence the macro-structure of a world society. Additionally, it might be worthwhile to focus on $\mathrm{ABE}$ as a labor market policy and operationalize trade asymmetries and real competition between countries.

\section{Appendix}

See Fig. 4.5 and Tables 4.2, 4.3.

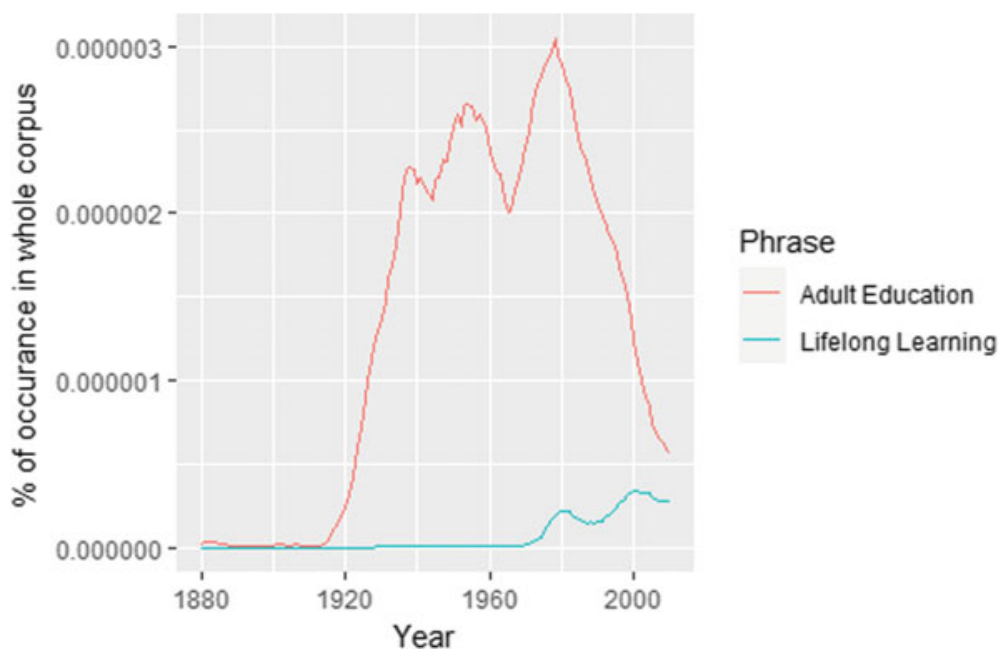

Fig. 4.5 Google Ngram for "adult education" and "lifelong learning" 
Table 4.2 Diffusion of adult basic education results with non-normalized exposure in network of colonial legacies

\begin{tabular}{|c|c|c|c|c|c|c|}
\hline & (1) & (2) & (3) & (4) & (5) & (6) \\
\hline 1880-1948 & $0.0003^{* * *}$ & $0.0003^{* * *}$ & $0.0001^{* * *}$ & $0.0001^{* * *}$ & $0.0001^{* * *}$ & $0.0003^{* * *}$ \\
\hline 1949-1959 & $0.009^{\star * *}$ & $0.007^{* * *}$ & $0.002^{* * *}$ & $0.002^{\star * *}$ & $0.004^{\star * *}$ & $0.007^{* * *}$ \\
\hline 1960-1971 & $0.003^{* * *}$ & $0.002^{* * *}$ & $0.0004^{* * *}$ & $0.0004^{* * *}$ & $0.001^{* * *}$ & $0.003^{* * *}$ \\
\hline 1972-1984 & $0.005^{* * *}$ & $0.003^{* * *}$ & $0.001^{* * *}$ & $0.001^{* * *}$ & $0.002^{\star * *}$ & $0.003^{* * *}$ \\
\hline 1985-1996 & $0.008^{* * *}$ & $0.004^{* * *}$ & $0.001^{* * *}$ & $0.001^{* * *}$ & $0.005^{* * *}$ & $0.008^{* * *}$ \\
\hline 1997-2010 & $0.003^{* * *}$ & $0.002^{* * *}$ & $0.001^{* * *}$ & $0.0005^{* * *}$ & $0.004^{* * *}$ & $0.005^{* *}$ \\
\hline $\begin{array}{l}\text { trade existed } \\
(=1 \text {, else }= \\
0)\end{array}$ & & & $7.115^{* *}$ & $7.199^{* *}$ & 3.126 & 2.224 \\
\hline $\begin{array}{l}\text { cultural } \\
\text { spheres } \\
\text { netw.: w. } \\
\text { exposure } \\
\text { (lag } 1 \text { year) }\end{array}$ & $59.900^{* *}$ & $114.031^{* * *}$ & $195.071^{* * *}$ & $66.091^{*}$ & 9.197 & 16.555 \\
\hline $\begin{array}{l}\text { colonies } \\
\text { netw.: w. } \\
\text { exposure }\end{array}$ & & $5.732^{\star * *}$ & $5.761^{* * *}$ & $5.819^{* * *}$ & $8.038^{* *}$ & $6.877^{* \star *}$ \\
\hline $\begin{array}{l}\text { trade net: w. } \\
\text { exposure } \\
\text { (lag } 1 \text { year) }\end{array}$ & & & $0.175^{* *}$ & $0.147^{* *}$ & 0.447 & 0.162 \\
\hline $\begin{array}{l}\text { spatial } \\
\text { proximity } \\
\text { netw.: w. } \\
\text { exposure } \\
\text { (lag } 1 \text { year) }\end{array}$ & & & & 4.909 & 1.601 & 1.652 \\
\hline $\begin{array}{l}\text { GDP per } \\
\text { capita / } \\
\text { US } \$ 10,000\end{array}$ & & & & & 1.080 & 1.095 \\
\hline democratization & & & & & 1.046 & 1.051 \\
\hline $\begin{array}{l}\text { percentage } \\
\text { adults w/o } \\
\text { schooling }\end{array}$ & & & & & 0.991 & 0.980 \\
\hline $\begin{array}{l}\text { trade net: } w . \\
\text { exposure: } \\
\text { percentage } \\
\text { adults w/o } \\
\text { schooling }\end{array}$ & & & & & & 1.035 \\
\hline Observations & 18,190 & 18,190 & 18,190 & 18,190 & 14,445 & 14,445 \\
\hline $\begin{array}{l}\text { Log } \\
\text { Likelihood }\end{array}$ & -598.944 & -586.811 & -577.593 & -576.803 & -472.636 & -470.642 \\
\hline $\begin{array}{l}\text { Akaike Inf. } \\
\text { Crit }\end{array}$ & 1211.888 & 1189.621 & 1175.186 & 1175.605 & 973.272 & 971.284 \\
\hline
\end{tabular}


Table 4.3 Diffusion of adult basic education. Results without considering USSR countries. Model 2 uses non-normalized exposure in network of colonial legacies

\begin{tabular}{lll}
\hline & $(1)$ & $(2)$ \\
\hline $1880-1948$ & $0.0004^{* * *}$ & $0.0004^{* * *}$ \\
$1949-1959$ & $0.003^{* * *}$ & $0.003^{* * *}$ \\
$1960-1971$ & $0.004^{* * *}$ & $0.004^{* * *}$ \\
$1972-1984$ & $0.007^{* * *}$ & $0.007^{* * *}$ \\
$1985-1996$ & $0.014^{* *}$ & $0.014^{* *}$ \\
$1997-2010$ & $0.009^{* *}$ & $0.008^{* *}$ \\
trade existed (=1, else $=0)$ & 1.138 & 1.166 \\
cultural spheres netw.: w. exposure (lag 1 year) & 27.446 & $29.213^{+}$ \\
colonies netw.: w. exposure & 1.642 & \\
non-normalized, colonies netw.: w. exposure & & 1.278 \\
trade net: w. exposure (lag 1 year) & 0.134 & 0.157 \\
spatial proximity netw.: w. exposure (lag 1 year) & 0.961 & 1.203 \\
GDP per capita / US\$10,000 & 1.077 & 1.049 \\
democratization & $1.089^{+}$ & 1.075 \\
percentage adults w/o schooling & 0.985 & 0.985 \\
trade net: w. exposure: percentage adults w/o & $1.042^{+}$ & $1.043^{+}$ \\
schooling & & \\
Observations & 13,675 & 13,675 \\
Log Likelihood & -429.564 & -429.564 \\
Akaike Inf. Crit & 889.128 & 889.128 \\
\hline
\end{tabular}

Note ${ }^{+} p<0.1 ;{ }^{*} p<0.05 ;{ }^{*} p<0.01 ;{ }^{* * *} p<0.001$

\section{Literature}

African Union. 2016. Continental Education Strategy for Africa (CESA). CESA 16-25.

Barbieri, Katherine, and Omar M. G. Keshk. 2016. "Correlates of War Project Trade Data Set Codebook, Version 4.0.” Last accessed March 24, 2021. http://correlatesofwar.org.

Barro, Robert J., and Jong-Wha Lee. 2015. Education Matters: Global Schooling Gains from the 19th to the 21st Century. New York: Oxford University Press. Becker, Bastian. 2019. "Colonial Dates Dataset (COLDAT)." https://doi.org/ 10.7910/DVN/T9SDEW.

Besche-Truthe, Fabian, Helen Seitzer, and Michael Windzio. 2020. "Cultural Spheres-Creating a Dyadic Dataset of Cultural Proximity." SFB 1342 Technical Paper Series 5. Bremen. 
Bhola, Harbans S. 1989. World Trends and Issues in Adult Education. London: Kingsley.

Boli, John, Francisco O. Ramirez, and John W. Meyer. 1985. "Explaining the Origins and Expansion of Mass Education." Comparative Education Review 29 (2): 145-170.

Dale, Roger. 1999. "Specifying Globalization Effects on National Policy: A Focus on the Mechanisms." Journal of Education Policy 14 (1): 1-17.

Dobbin, Frank, Beth Simmons, and Geoffrey Garrett. 2007. "The Global Diffusion of Public Policies: Social Construction, Coercion, Competition, or Learning?” Annual Review of Sociology 33 (1): 449-472.

Elkins, Zachary, and Beth Simmons. 2005. "On Waves, Clusters, and Diffusion: A Conceptual Framework." The ANNALS of the American Academy of Political and Social Science 598 (1): 33-51.

European Council. 2011. "Council Resolution on a Renewed European Agenda for Adult Learning.” European Council, December 20.

Franzese, Robert J., and Jude C. Hays. 2006. "Strategic Interaction Among EU Governments in Active Labor Market Policy-Making." European Union Politics 7 (2): 167-189.

Gilardi, Fabrizio. 2016. "Four Ways We Can Improve Policy Diffusion Research." State Politics Policy Quarterly 16 (1): 8-21.

Griffiths, Tom G., and Robert F. Arnove. 2015. "World Culture in the Capitalist World-System in Transition." Globalisation, Societies and Education 13 (1): 88-108.

Griffiths, Tom G., and Robert Imre. 2013. Mass Education, Global Capital, and the World: The Theoretical Lenses of István Mészáros and Immanuel Wallerstein. New York, NY: Palgrave Macmillan.

Inklaar, Robert, Harmen de Jong, Jutta Bolt, and Jan van Zanden. 2018. "Rebasing 'Maddison': New Income Comparisons and the Shape of LongRun Economic Development." GDC Research Memorandum GD-174. Last accessed March 24, 2021. https://ideas.repec.org/p/gro/rugggd/gd-174. html.

Jahn, Detlef. 2006. "Globalization as 'Galton's Problem': The Missing Link in the Analysis of Diffusion Patterns in Welfare State Development." International Organization 60 (2): 401-431.

Jakobi, Anja P. 2009. International Organizations and Lifelong Learning: From Global Agendas to Policy Diffusion. Transformations of the State. Basingstoke: Palgrave Macmillan. 
Knoll, Joachim H. 2008. "Zur Geschichte der UNESCO-Weltkonferenzen für Erwachsenenbildung - von Helsingör (1949) bis Hamburg (1997).” Bildung und Erziehung 61 (2): 129-150.

Kuhlmann, Johanna, Delia González de Reufels, Klaus Schlichte, and Frank Nullmeier. 2020. "How Social Policy Travels: A Refined Model of Diffusion." Global Social Policy 20 (1): 80-96.

Lindert, Peter H. 2004. Growing Public: Social Spending and Economic Growth Since the Eighteenth Century. Cambridge, UK: Cambridge.

Lührmann, Anna, Marcus Tannenberg, and Staffan I. Lindberg. 2018. "Regimes of the World (RoW): Opening New Avenues for the Comparative Study of Political Regimes." Politics and Governance 6 (1): 60-77.

Maggetti, Martino, and Fabrizio Gilardi. 2016. "Problems (and Solutions) in the Measurement of Policy Diffusion Mechanisms." Journal of Public Policy 36 (1): 87-107.

Martens, Kerstin, and Michael Windzio. 2021. "The Global Development, Diffusion, and Transformation of Education Systems: Transnational Isomorphism and Cultural Spheres". In Global Pathways to Education-Cultural Spheres, Networks, and International Organizations, edited by Kerstin Martens and Michael Windzio, 1-35. Global Dynamics of Social Policy. Cham: Palgrave Macmillan.

Meyer, John W., John Boli, George M. Thomas, and Francisco O. Ramirez. 1997. "World Society and the Nation-State." American Journal of Sociology 103 (1): 144-181.

Obinger, Herbert, and Carina Schmitt. 2011. "Guns and Butter? Regime Competition and the Welfare State during the Cold War." World Politics 63 (2): 246-270.

OECD. 2012. "Lifelong Learning and Adults." In Education Today 2013: The OECD Perspective.

Paglayan, Agustina S. 2021. "The Non-Democratic Roots of Mass Education: Evidence from 200 Years:” American Political Science Review 115 (1): 179198.

Pfau-Effinger, Birgit. 2005. "Culture and Welfare State Policies: Reflections on a Complex Interrelation.” Journal of Social Policy 34 (1): 3-20.

Ramirez, Francisco O. 1989. "Reconstituting Children: Extension of Personhood and Citizenship." In Social Structure and Aging: Age Structuring in Comparative Perspective, edited by David I. Kertzer, and K. W. Schaie, 143-165. Hillsdale, NJ: L. Erlbaum Associates. 
Shields, Robin, and Francine Menashy. 2019. "The Network of Bilateral aid to Education 2005-2015." International Journal of Educational Development 64: 74-80.

Spilker, Niels. 2013. Lebenslanges Lernen als Dispositiv - Bildung, Macht und Staat in der neoliberalen Gesellschaft. Münster: Westfälisches Dampfboot.

Strang, David. 1991. "Adding Social Structure to Diffusion Models.” Sociological Methods \& Research 19 (3): 324-353.

Strang, David, and John W. Meyer. 1993. "Institutional Conditions for Diffusion." Theory and Society 22 (4): 487-511.

Swank, Duane. 2006. "Tax Policy in an Era of Internationalization: Explaining the Spread of Neoliberalism." International Organization 60 (4): 847-882.

Torres, Rosa M. 2009. From Literacy to Lifelong Learning: Trends, Issues and Challenges in Youth and Adult Education in Latin America and the Caribbean: Regional Synthesis Report. UNESCO Institute for Lifelong Learning.

UNESCO. 2015. Recommendation on Adult Learning and Education.

UNESCO. 2017. Education for Sustainable Development Goals: Learning Objectives. Paris.

UNESCO. 2018. Global Education Monitoring Report 2019. Paris.

UNESCO Institute for Statistics. 2012. International Standard Classification of Education: ISCED 2011. Montreal, Quebec: UNESCO Institute for Statistics.

Valente, Thomas W. 1995. Network Models of the Diffusion of Innovations. Second printing. Quantitative Methods in Communication. Cresskill, NJ: Hampton Press.

Weymann, Ansgar. 2016. Bildungsstaat: Aufstieg, Herausforderungen, Perspektiven. Stichworte: Wissen kompakt. Wiesbaden: Springer VS.

World Bank. 1995. Priorities and Strategies for Education: A World Bank Review. Washington, DC: The World Bank.

World Bank. 2003. Lifelong Learning in the Global Knowledge Economy: Challenges for Developing Countries: A World Bank Report. Directions in Development. Washington, DC: World Bank.

World Conference on Education for All. 1990. Meeting Basic Learning Needs: A Vision for the 1990s: World Conference on Education for All Background Document. Inter-Agency Commission (UNDO, UNESCO, UNICEF, WORLD BANK) for the World Conference on Education for All.

Yon, George G. V., and Thomas W. Valente. 2017. NetdiffuseR: Analysis of Diffusion and Contagion Processes on Networks. Zenodo. 
Open Access This chapter is licensed under the terms of the Creative Commons Attribution 4.0 International License (http://creativecommons.org/ licenses/by/4.0/), which permits use, sharing, adaptation, distribution and reproduction in any medium or format, as long as you give appropriate credit to the original author(s) and the source, provide a link to the Creative Commons license and indicate if changes were made.

The images or other third party material in this chapter are included in the chapter's Creative Commons license, unless indicated otherwise in a credit line to the material. If material is not included in the chapter's Creative Commons license and your intended use is not permitted by statutory regulation or exceeds the permitted use, you will need to obtain permission directly from the copyright holder.

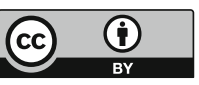

